\title{
The effects of long-term moderate exercise and Western-type diet on oxidative/nitrosative stress, serum lipids and cytokines in female Sprague Dawley rats
}

\author{
Maria Donatella Semeraro ${ }^{1}$. Gunter Almer ${ }^{1}$. Melanie Kaiser ${ }^{1}$. Sieglinde Zelzer ${ }^{1}$. Andreas Meinitzer ${ }^{1}$. \\ Hubert Scharnagl ${ }^{1} \cdot$ Simon Sedej ${ }^{2,3,4} \cdot$ Hans-Jürgen Gruber ${ }^{1} \cdot$ Markus Herrmann $^{1}$
}

Received: 1 March 2021 / Accepted: 5 July 2021 / Published online: 28 July 2021

(c) The Author(s) 2021

\begin{abstract}
Purpose Regular exercise reduces obesity and the risk of cardiovascular disease. However, health-promoting benefits of physical activity are commonly associated with increased inflammation and oxidative stress. Here, we tested whether constant moderate exercise is able to prevent or attenuate the oxidative/nitrosative stress, inflammation, and serum lipids in lean and obese rats.

Methods Four-month-old female Sprague Dawley rats received standard or a high-fat diet. Animals were subjected to a physical activity protocol, consisting of 30 min forced treadmill exercise for 5 consecutive days per week during 10 months. Baseline and sedentary (non-exercised) rats were used as controls. Lipids, oxidized low-density lipoprotein cholesterol, nitric oxide metabolites, and pro- and anti-inflammatory markers were measured in blood collected upon euthanasia.

Results At variance to young baseline control rats, 14-month-old animals fed normal diet had increased plasma lipid levels, including total cholesterol and triglycerides, which were further elevated in rats that consumed a high-fat diet. While treadmill exercise did not lower the amount of serum lipids in standard diet group, forced physical activity reduced non-high-density lipoprotein cholesterol in response to high-fat diet feeding. Exercised rats fed standard diet or high-fat diet had lower abundancy of nitric oxide metabolites, which coincided with increased levels of oxidized low-density lipoprotein cholesterol. Accordingly, the amount of nitric oxide metabolites correlated inversely with oxidized low-density lipoprotein cholesterol and homo-arginine. Exercise significantly reduced inflammatory cytokines in high-fat diet fed rats only.

Conclusion Our study suggests that regular exercise alters the equilibrium between oxidative and anti-oxidative compounds and reduces pro-inflammatory cytokines.
\end{abstract}

Keywords Long-term moderate exercise · Western-type diet · Oxidized LDL $\cdot$ Nitric oxide $\cdot$ Nitric oxide synthase Sprague Dawley rats

Markus Herrmann

markus.herrmann@medunigraz.at

1 Clinical Institute of Medical and Chemical Laboratory Diagnostics, Medical University of Graz, 15/1

Auenbruggerplatz, 8036 Graz, Austria

2 Department of Cardiology, Medical University of Graz, 8036 Graz, Austria

3 BioTechMed Graz, 8010 Graz, Austria

4 Faculty of Medicine, University of Maribor, 2000 Maribor, Slovenia

\section{Introduction}

Cardiovascular disease (CVD) is a major cause of morbidity and mortality in Western societies and developing countries [1]. Modifiable risk factors, such as obesity and sedentarism are highly prevalent in patients with CVD, and both can be improved by safe and effective lifestyle interventions [2]. Such lifestyle factors are diet and exercise that affect the concentration of low-density lipoproteins (LDL), which are known metabolic driver of CVD, such as atherosclerosis [3-5]. In addition, it is well established that elevated concentrations of LDL cholesterol (LDL-C) promote atherosclerosis and increase the risk of non-fatal and lethal CVD events. LDL-C is subjected to oxidation, resulting in 
the formation of oxidized LDL (oxLDL), which is thought to be more aggressive than non-oxidized LDL in inducing atherogenesis [6, 7].

Elevated oxidative stress characterized by an increased generation of radical oxygen species (ROS) is a common manifestation in patients with CVD, obesity, and diabetes mellitus. These highly reactive compounds can modify many biomarkers including LDL-C [8-10]. The modification of LDL-C by oxidation promotes the receptor-mediated uptake of oxLDL by macrophages, thereby causing cholesterol accumulation in the vasculature. Previous studies in humans and animals indicate that Western diet and physical inactivity induce free radical production, which may enhance the susceptibility of LDL to oxidation $[3,4,11]$. One of the principal pathways involved in the adaptation to exercise is nitric oxide (NO) signalling. NO triggers vasodilation and, thus, can mitigate the high shear stress during exercise. Furthermore, NO is involved in several other physiological and pathological processes, such as cell inflammation and adhesion as well as angiogenesis [12-15]. NO is synthetised by three isoforms of the enzyme NO synthase (NOS), including neuronal (nNOS or NOS-1), inducible (iNOS or NOS-2), and endothelial isoform (eNOS or NOS-3). All of them are constitutively but not exclusively expressed in the cardiovascular system [10]. In particular, eNOS requires dimerization to maintain its normal function but under certain conditions the reduction of molecular oxygen by eNOS is not coupled anymore with the oxidation of the substrate L-arginine (L-arg), thus resulting in the production of superoxide instead of NO [10]. The main eNOS uncoupling motifs are the cofactor of $\mathrm{NO}$ synthesis, tetrahydrobiopterin (BH4), reduced bioavailability of L-arg, or high levels of the endogenous NOS inhibitor, asymmetrical dimethyl-arginine (ADMA) [8].

Although regular exercise is proven to reduce CVD risk and promote health benefits [12, 16-19], constant physical activity also increases the production of free radicals and oxidative stress $[4,9]$. This raises the question as to whether exercise-induced oxidative stress is beneficial or detrimental. In this regard, obese and normal-weight human adults have reportedly comparable oxLDL concentrations [20], whereas other studies showed that body weight reduction after the bariatric surgery or regular moderate exercise decrease oxLDL $[21,22]$. In contrast, a single intensive exercise session appears to increase the susceptibility of LDL and other lipoproteins to oxidation in healthy adults [3, 4]. Thus far, a single in vivo study explored the effects of HFD and regular physical activity on plasma lipids, oxidative/nitrosative stress and LDL oxidation. Specifically, Elmas et al. showed that rats consuming a HFD exhibit increased oxidative stress in aortic and myocardial tissue [2]. Regular exercise appears to modify the balance of antioxidants and oxidants as well as NO metabolism in these tissues. However, it remains elusive whether constant moderate exercise is able to prevent or attenuate the oxidative/nitrosative stress, inflammation, and serum lipids in lean and obese rats.

In the present study, we investigated the impact of HFD and regular moderate exercise on the oxidative/nitrosative stress, serum lipids and cytokines. For this purpose, blood samples from young and old Sprague Dawley female rats that were subjected to forced treadmill exercise sessions for 10 months in combination with a HFD or ND were analysed.

\section{Materials and methods}

\section{Animal model}

Four-month-old healthy female SD rats $(n=120)$ with an average body weight of approximately $300 \mathrm{~g}$ were purchased from Janvier Labs (France) and kept in groups of three animals per cage under constant conditions on a $12 \mathrm{~h}$ light and $12 \mathrm{~h}$ dark cycle in the institutional animal facility. The decision to work with female animals aimed to avoid gender effects and to reduce the risk of dropouts due to aggressive behaviour between animals. After 1 week of acclimatization, the animals were randomly assigned to receive a standard diet (ND) (Altromin, Germany) with $3.23 \mathrm{kcal} / \mathrm{kg}$ and $11 \%$ fat or a custom-designed beef-tallow high-fat diet (HFD), rich in saturated fatty acids (SFA), in particular C16:0 and C18:0, with $5.15 \mathrm{kcal} / \mathrm{kg}$ and 60\% fat (Table 1; ssniff, Germany). Saturated fatty acids (SFA) and mono-unsaturated fatty acids (MUFA) are present in a ratio of 1:1. While the ratio of SFA and poly-unsaturated fatty acids (PUFA)

Table 1 Composition of the high-fat diet

\begin{tabular}{|c|c|c|c|}
\hline \multicolumn{2}{|l|}{ Fatty acids } & \multicolumn{2}{|l|}{ Vitamins } \\
\hline Saturated fatty acids & $\%$ & Antioxidant & Per kg \\
\hline C 12:0 & 0.04 & Vitamin A & $15,000 \mathrm{IU}$ \\
\hline C $14: 0$ & 1.18 & Vitamin E & $150 \mathrm{mg}$ \\
\hline C 16:0 & 8.27 & & \\
\hline C 17:0 & 0.38 & Others & \\
\hline C $18: 0$ & 6.06 & Vitamin $\mathrm{D}_{3}$ & $1500 \mathrm{IU}$ \\
\hline \multirow[t]{2}{*}{ C $20: 0$} & 0.04 & Vitamin $\mathrm{K}$ (as MNB) & $20 \mathrm{mg}$ \\
\hline & & Thiamine $\left(\mathrm{B}_{1}\right)$ & $25 \mathrm{mg}$ \\
\hline \multicolumn{2}{|l|}{ Mono-unsaturated fatty acids } & Riboflavin $\left(\mathrm{B}_{2}\right)$ & $16 \mathrm{mg}$ \\
\hline C $16: 1$ & 1.33 & Pyridoxine $\left(\mathrm{B}_{6}\right)$ & $16 \mathrm{mg}$ \\
\hline \multirow[t]{2}{*}{ C $18: 1$} & 12.29 & Cobalamin $\left(\mathrm{B}_{12}\right)$ & $30 \mu \mathrm{g}$ \\
\hline & & Nicotinic acid & $47 \mathrm{mg}$ \\
\hline \multicolumn{2}{|l|}{ Poly-unsaturated fatty acids } & Pantothenic acid & $55 \mathrm{mg}$ \\
\hline C $18: 2$ & 2.53 & Folic acid & $16 \mathrm{mg}$ \\
\hline \multirow[t]{2}{*}{ C $18: 3$} & 0.34 & Biotin & $300 \mu \mathrm{g}$ \\
\hline & & Choline & $920 \mathrm{mg}$ \\
\hline
\end{tabular}

Fatty acids and antioxidant vitamins content 
is close to 5:1. The HFD composition was based on previous studies [23-25]. Food and tap water were provided ad libitum.

\section{Experimental design and treatment}

Animals were randomly allocated to 5 groups, each consisting of 24 animals. The rats in group 1 were sacrificed after the acclimatization period and served as a baseline control (BL). Ninety-six animals were divided in a 1:1 ratio, fed ND or HFD and subjected to the 10-month study protocol as follows: half of the rats fed ND or HFD performed 30-min running exercise sessions on a treadmill (Panlab, Spain) on 5 consecutive days (indicate at what time of the day) followed by 2 days of rest. The running speed was constant and set at $30 \mathrm{~cm} / \mathrm{s}$. The training protocol was based on previous experimental studies [26-29]. The animals that did not exercise throughout the entire study period were used as sedentary controls.

\section{Euthanasia and sample preparation}

At the end of the 10-month study period, blood was drawn by heart puncture under deep isoflurane anaesthesia (Forane, Abbott, Austria). Also for the baseline animals, the blood was collected only once at the time of sacrification. Blood and plasma were collected using S-Monovette Serum-Gel tubes and S-Monovette Plasma-EDTA tubes (Sarstedt, Nümbrecht, Germany), respectively. Samples were centrifuged at $2000 \mathrm{~g}$ for $12 \mathrm{~min}$ at room temperature, aliquoted and stored at $-80{ }^{\circ} \mathrm{C}$ until the analysis. Blood collections and consequently serum analyses were performed in a nonfasting state.

\section{Evaluation of the oxidative/nitrosative stress}

The circulating oxLDL concentration was determined in serum $(100 \mu \mathrm{l})$ with a rat-specific commercial Sandwich ELISA kit (USCN Life Sciences, Texas) according to the manufacturer's instructions. This assay uses rat polyclonal antibodies against oxLDL and has a measurement range between 31.2 and $2000 \mathrm{pg} / \mathrm{ml}$. In this range, intra- and interassay imprecision is below $<12 \%$. NO was estimated in serum $(100 \mu \mathrm{l})$ by measuring the degradation products nitrite $\left(\mathrm{NO}_{2}{ }^{-}\right)$and nitrate $\left(\mathrm{NO}_{3}{ }^{-}\right)$using a commercial photometric method (NO quantification kit, Active Motif, California) on a FlexStation3 (Molecular devices, California). In addition, plasma concentrations of homo-arginine (h-arg), ADMA and symmetrical dimethyl-arginine (SDMA) were quantified by a reverse-phase high-pressure liquid chromatography (HPLC) method as described previously [30, 31].

\section{Assessment of systemic inflammatory markers}

A profile of 22 inflammatory markers and chemokines, including Regulated and Normal T-cell Expressed and Secreted (RANTES), eotaxin, macrophage inflammatory protein $1 \alpha$ (MIP-1 $\alpha$ ), monocyte chemoattractant proteins 1 and 3 (MCP-1 and 3), tumour necrosis factor $\alpha($ TNF- $\alpha)$, interferon $\gamma($ IFN- $\gamma)$, IFN- $\gamma$-inducible protein (IP-10), and interleukins (IL-1 $\beta$, IL-2, IL-5, IL-6, IL-10, IL-12, IL-17) were determined in $25 \mu \mathrm{l}$ of serum with a preconfigured multiplex immunoassay kit (ThermoFisher Scientific, Austria) using the BioPlexTM 200 detection system (Bio-Rad, Austria). The activity of matrix metalloproteinases (MMPs) was measured through an enzymatic reaction using a Mca-PLGL-Dpa-AR- $\mathrm{NH}_{2}$-fluorogenic peptide substrate (R\&D Systems, Canada). Serum $(90 \mu \mathrm{l})$ was incubated with the diluted working solution $(10 \mu \mathrm{l})$ for $20 \mathrm{~min}$ at room temperature. The fluorescent signal was detected at $320 \mathrm{~nm}$ excitation and 405 emission wavelength using the photometer FLUOstar OPTIMA (BMG Labtech, Germany).

\section{Assessment of lipid metabolism and adipocytokines}

The serum lipid profile was determined on fully automated Olympus AU640 analyser (Olympus, Hamburg, Germany) using commercial assays. Briefly, total cholesterol (TC), triglycerides (TG), phospholipids (PL), non-esterified fatty acids (NEFA), and HDL cholesterol (HDL-C; homogeneous assay) were measured using enzymatic methods and reagents from Diasys (Holzheim, Germany). The instrument was calibrated using secondary standards from Roche Diagnostics (Mannheim, Germany; for TC, TG) and Dyasis (Holzheim, Germany; for FC, PL). Insulin growth factor-1 (IGF-1), leptin and adiponectin were evaluated in serum by commercial sandwich ELISAs (Demeditec Diagnostics Gmbh, Germany) according to the manufacturer's instructions. Finally, resistin was quantified using a sandwich enzyme immunoassay from BioVendor-Laboratorní medicína a.s. (Brno, Czech Republic).

\section{Statistical analyses}

Data are presented as means \pm standard deviations. The differences between groups were assessed using two-tailed Student's $t$ test for dependent or independent samples or Mann-Whitney $U$ test depending on the distribution of the data. Correlations between variables were determined by linear regression analysis according to Pearson ( $r$, Pearson correlation coefficient; $p$, univariate ANOVA). $p$ value of $<0.05$ was considered statistically significant. Analyses 
were performed by explorative data analyses using SPSS for Windows $\left(\mathrm{IBM}^{\oplus} \mathrm{SPSS}^{\odot}\right.$ Statistics, version 25).

\section{Results}

\section{Exclusion criteria and body weight}

From the 120 rats included in the study, 6 rats had to be sacrificed before the end of exercise protocol because of illness, while additional 18 animals developed tumours and, thus, were excluded from the analysis (Fig. 1) [32]. Tumours were more frequent in animals fed high-fat than standard diet (16 vs. 2 rats). At the end of the study, 96 animals were included in the analysis. All animals had significantly increased body weight as compared to the baseline group (Fig. 2a, $p<0.001$ ). However, this increase in body weight was markedly higher in response to HFD than ND feeding. Also organ weights increased with age and HFD (Table 2).

The exercise protocol was well tolerated in all animals and reduced the weight gain in the ND animals $(p<0.01)$, but not in HFD animals. Moreover, regular moderate exercise induced an increase of myocardial and hepatic weight in HFD animals, but not in ND animals.

\section{Lipid profile}

Serum lipids are established risk factors of atherosclerosis and CVD that are affected by lifestyle factors, such as diet and physical activity [3-5]. Therefore, we first explored the effects of HFD and exercise on serum lipids. After 10 months of intervention, average TC and TG concentrations were significantly higher compared to baseline, regardless of diet and exercise (Fig. 2b, c). HFD animals showed additional alterations of the lipid profile beyond simple age-related changes. TG and NEFA were significantly higher than in ND animals, whereas non-HDL-C was lower (Fig. 2c, d, f). Exercise induced a decrease of TC and HDL-C in HFD, but not ND animals (Fig. 2b, e). All other lipid parameters were comparable between sedentary and exercising animals in both diet groups.

In an attempt to explore potential mechanism that mediate the changes in plasma lipids, correlation analyses have been performed. At study end, body weight was positively correlated with TG $(r=0.598 ; p<0.001)$,

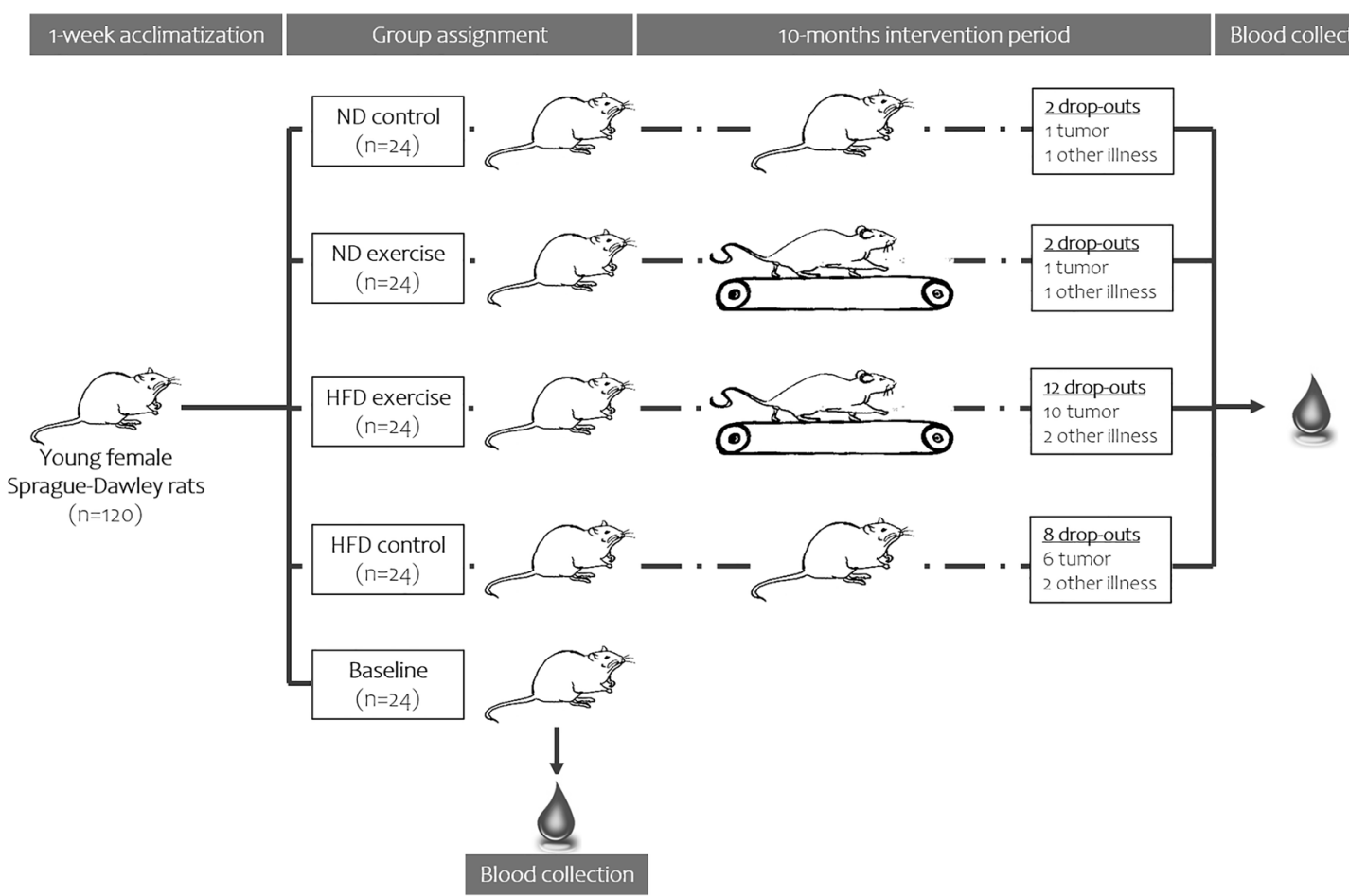

Fig. 1 The experimental design. One-hundred and twenty young female Sprague Dawley rats were randomly allocated into 5 groups, each consisting of 24 animals. The animals in the baseline control group were euthanized after the acclimatization period. The remain of ninety-six animals were divided in a 1:1 ratio and fed ND or HFD and subjected to a 10-month study protocol as follows: half of the rats fed ND or HFD performed 30-min running exercise sessions on a treadmill. Six animals (2 vs. 4 rats fed ND and HFD, respectively) died prior to the end of the study and eighteen more ( 2 vs. 16 rats under ND and HFD) had to be excluded due to the development of tumours 


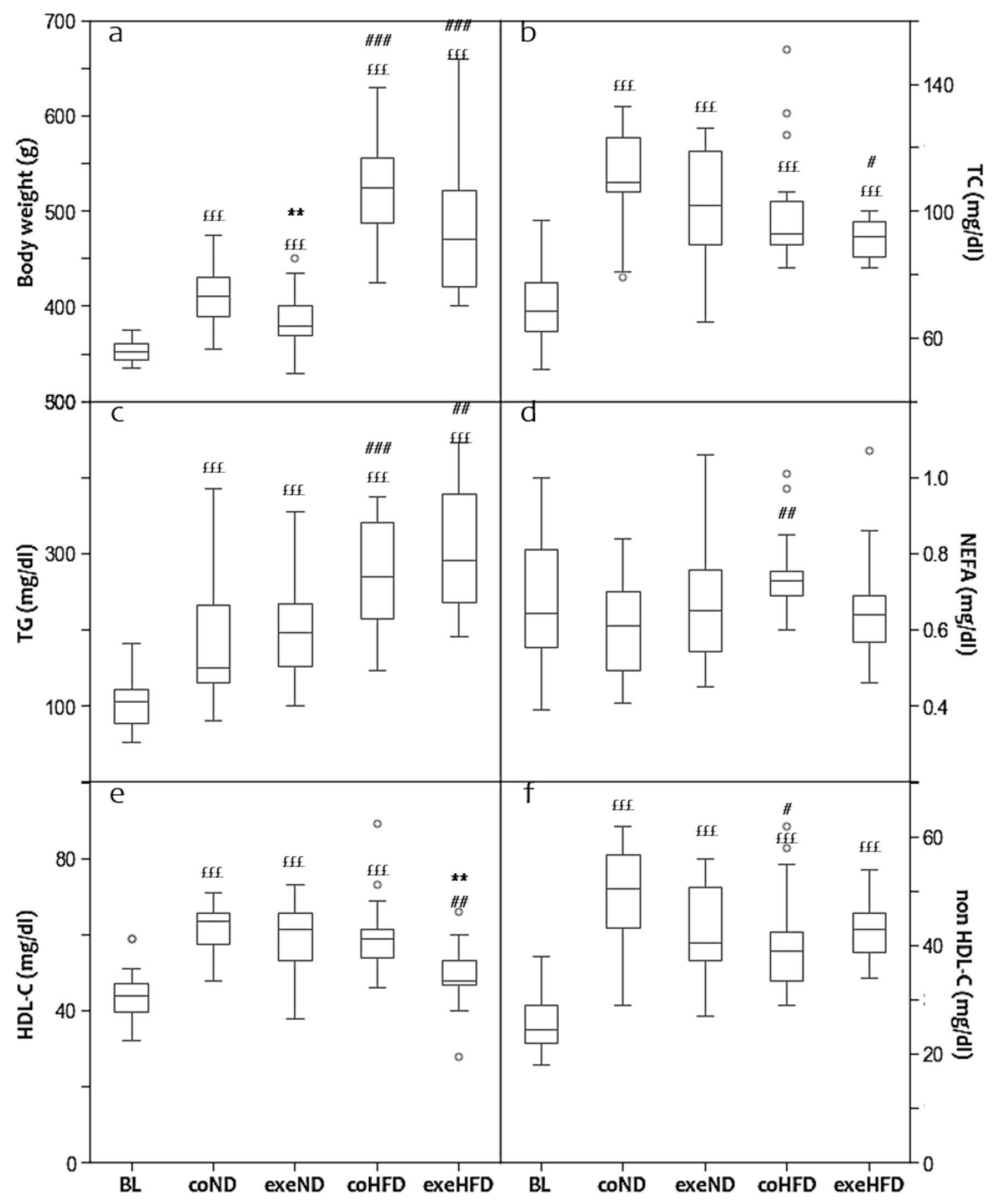

Fig. 2 Box and Whisker Blot of the body weight (a) and the lipid profile (b-f) after the 10 months study period. ** $p<0.01$ compared to appropriate sedentary control group; ${ }^{\#} p<0.05$, ${ }^{\# \#} p<0.01$,

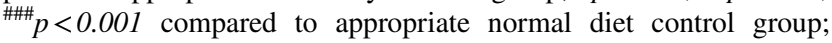

${ }^{£ £ £} p<0.001$ compared to baseline control group. The study groups have been abbreviated as follows: baseline group (BL), control normal diet (coND), exercise normal diet (exeND), control high fat diet (coHFD) and exercise high-fat diet (exeHFD)

NEFA $(r=0.238 ; p=0.025)$ and non-HDL-C $(r=0.271$; $p=0.010)$, whereas TC $(r=-0.291 ; p=0.006)$ and HDL-C $(r=-0.365 ; p<0.001)$ were inversely correlated to adiponectin.

\section{Oxidative/nitrosative stress}

Advanced age, obesity and physical inactivity are known to modulate the equilibrium between oxidant and antioxidant 


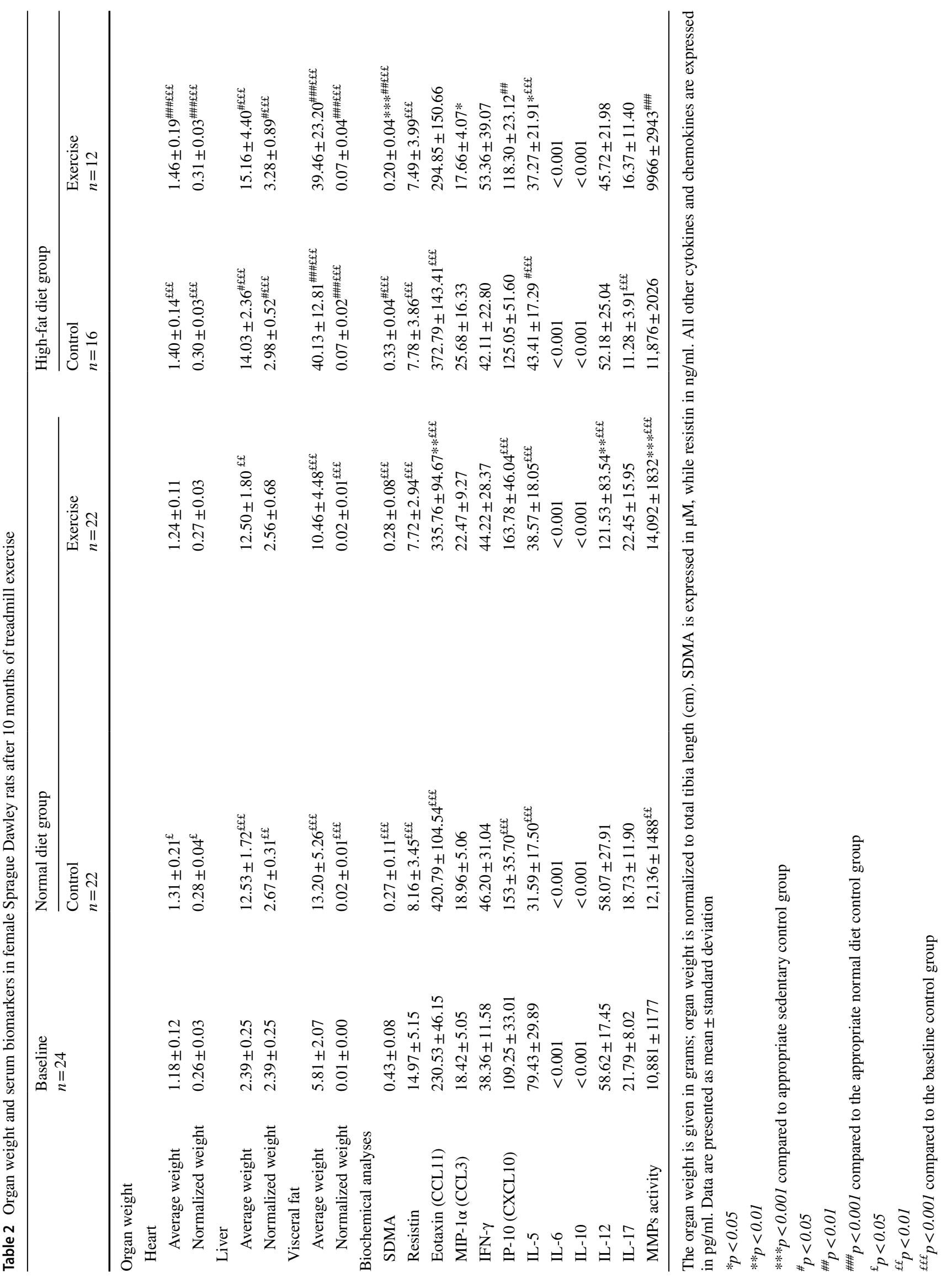




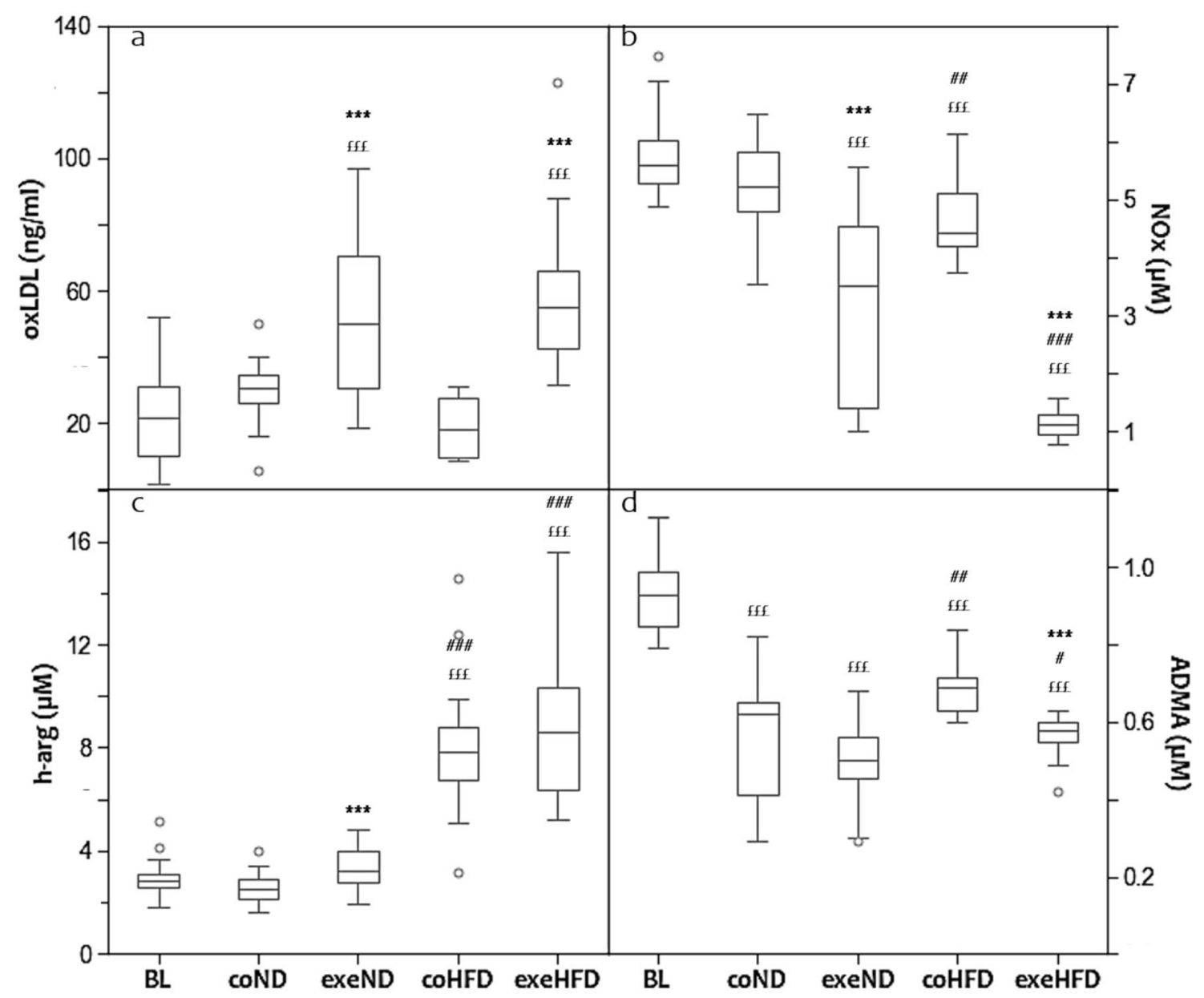

Fig. 3 Box and Whisker Blot of oxidized LDL (a). ***p $<0.001$ compared to appropriate sedentary control group; ${ }^{£ f £} p<0.001$ compared to baseline control group. Box and Whisker Blot of nitric oxide metabolites $(\mathbf{b})$. $* * * p<0.001$ compared to appropriate sedentary control group; ${ }^{\# \#} p<0.01,{ }^{\# \#} p<0.001$ compared to appropri-

compounds, with consequent alterations of lipid peroxidation and NOS function [8-10]. Therefore, we analysed the effects of HFD and exercise on oxLDL and NOx. Figure 3 shows that age and diet had a substantial effect neither on oxLDL nor on NOx (Fig. 3a, b). Exercise instead altered both biomarkers significantly. After 10 months of regular training, oxLDL was increased in ND and HFD by $44 \%$ and $68 \%$, respectively. In contrast, NOx was markedly lower in exercising animals with the lowest concentrations in the HFD group.

To corroborate the NOx results, we also measured the non-proteogenic amino acid h-arg, a substrate of NOS for the production of NO, and ADMA, a competitive inhibitor of NOS. h-arg was significantly higher in HFD animals than in ND and baseline controls (Fig. 3c). Exercise increased h-arg in ND animals, but not in HFD animals. The serum concentrations of ADMA were highest at baseline and decreased with age. This decrease was less pronounced in HFD than ate normal diet control group; ${ }^{£ f f} p<0.001$ compared to baseline control group. Box and Whisker Blot of homo-arginine and ADMA (c-d). ${ }^{* * *} p<0.001$ compared to appropriate sedentary control group; ${ }^{\#} p<0.05,{ }^{\# \#} p<0.01$ compared to appropriate normal diet control group; ${ }^{\text {ff }} p<0.001$ compared to baseline control group

in ND animals. Exercise reduced ADMA in the HFD group, but not in the ND group (Fig. 3d, $p<0.001$ ).

Considering that oxidative stress and NOS function are linked with each other, we performed linear regression analyses that showed a strong inverse association between oxLDL and NOx (Fig. 4a). An inverse relationship was also found between h-arg and NOx (Fig. 4b, $r=-0.453 ; p<0.001$ ). ADMA and SDMA were positively related to NOx with (ADMA $v s$. NOx, $r=0.401 ; p<0.001$ ) and (SDMA $v s$. NOx, $r=0.459 ; p<0.001)$, but inversely associated with oxLDL with $(r=-0.338 ; p<0.001)$ and $(r=-0.274 ; p=0.009)$, respectively.

\section{Effects of physical activity and diet on cytokines and chemokines}

Dyslipidaemia and oxidative/nitrosative stress are established drivers of chronic systemic inflammation, an 


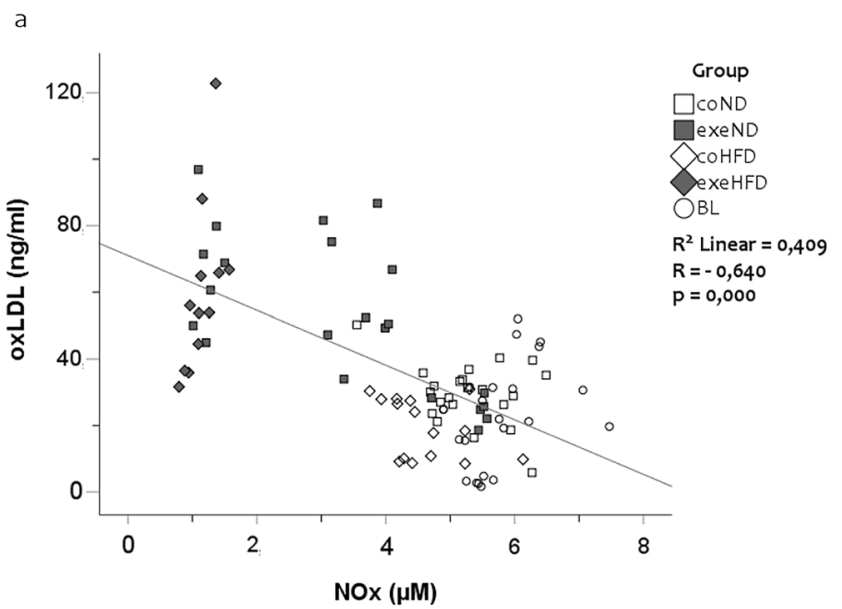

b

Fig. 4 Simple Scatter Dot Plot of the linear regression analysis with $r=-0.640$ and $p=0.000$ between oxidized LDL-C and nitric oxide metabolites (a) and $r=-0.453$ and $p=0.000$ between h-arg and nitric oxide metabolites (b)

important factor in the pathogenesis of atherosclerosis [6, 7]. To study the immunological response of HFD and physical activity, we analysed a broad panel of pro- and antiinflammatory cytokines (Fig. 5). Regular treadmill exercise reduced the serum concentrations of the pro-inflammatory cytokines, such as TNF- $\alpha$, IL- $1 \beta$ and IL- 2 in rats consuming HFD, but not those fed ND (Fig. 5b, e, f). All other cytokines were not significantly affected by exercise. Age and diet alone had no significant effects on the serum concentrations of the measured pro-and anti-inflammatory cytokines (Table 2).

Chemokines are secreted signalling proteins that mediate the migration of immune cells in response to pro-inflammatory cytokines [33]. In the present study, several proinflammatory chemokines, including RANTES, MCP-1 and 3, were measured. In 14-month-old sedentary ND and HFD animals, the average serum concentrations of RANTES and MCP-3 were significantly higher than in young baseline controls (Fig. 5a, d). Regular exercise attenuated this agerelated increase irrespective of diet. MCP-1 showed similar trends, but due to a greater inter-individual variability of this marker, significant effects were present only in HFD animals (Fig. 5c).

\section{Adipocytokines}

Adipocytokines, such as adiponectin, leptin, and IGF-1 are key regulators of energy metabolism and fat stores that are centrally involved in the pathomechanistic sequaele of adipositas and obesity [34, 35]. Furthermore, they have immune-modulatory effects [36]. In the present study, age, diet, and exercise had profound effects on the serum concentrations of IGF-1, adiponectin, and leptin (Fig. 6). At the end of the 10-month protocol, IGF-1 concentration was approximately 50\% lower than in young baseline controls, irrespective of diet (Fig. 6a). Exercising animals fed HFD, had slightly higher IGF-1 concentrations than their respective controls. In contrast, leptin was markedly higher in old than in young animals (Fig. 6c). The age-related increase in serum leptin was substantially amplified by HFD. Exercise reduced serum leptin concentrations slightly in both diet groups. Adiponectin was not affected by age and exercise in ND animals, but increased in HFD animals (Fig. 6b). This increase was greater in exercising HFD animals. Resistin decreased with age in HFD and ND animals $(p<0.001)$. In both dietary groups, exercising animals had even lower resistin serum concentrations than sedentary counterparts.

\section{Discussion}

The present study shows that long-term moderate exercise reduces the body weight gain and NOx but increases oxLDL in normal-weight and obese rats. Administering HFD to sedentary animals resulted in a marked increase in body weight gain and triglycerides; however, it failed to systematically alter oxLDL, NOx or any other lipid profile parameter.

In the SD rats used in this project, long-term moderate running exercise did not change TC, HDL-C, and nonHDL-C. In HFD fed animals, TG was slightly reduced by exercise. Furthermore, exercise increased oxLDL in both dietary groups. These results are in contrast to most previous studies in humans and rodents where regular moderate endurance exercise reduced TG, TC and LDL-C, whereas HDL-C increased [2, 26, 37-39]. However, the results of individual studies may vary substantially $[4,37,40]$ and comparability between studies is limited by different experimental settings. For example, Elmas et al. analysed the 


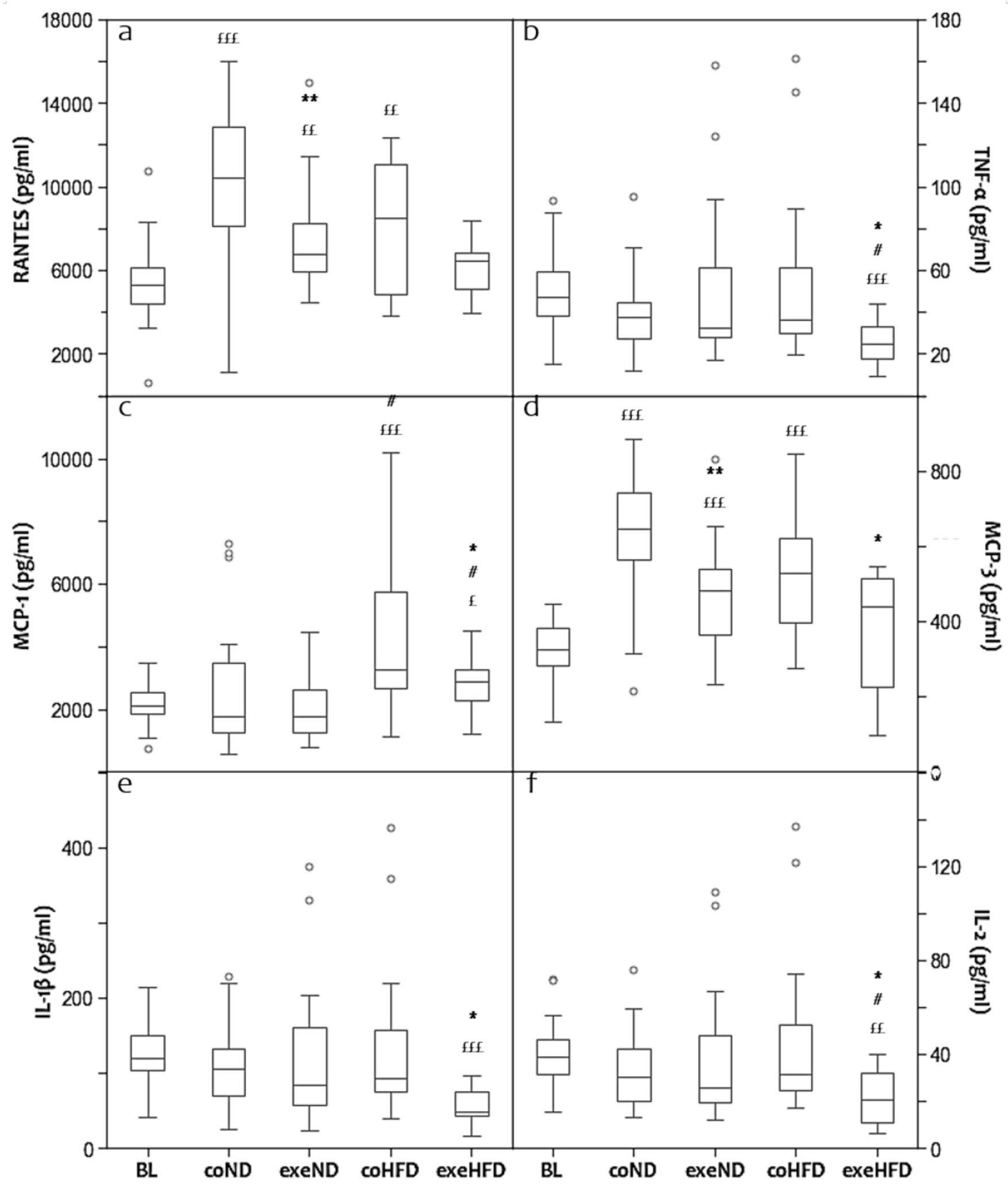

Fig. 5 Box and Whisker Blot of the panel of cytokines and chemokines $(\mathbf{a}-\mathbf{f}) .{ }^{*} p<0.05,{ }^{*} p<0.01$ compared to appropriate sedentary control group; ${ }^{\#} p<0.05$ compared to appropriate normal diet control group. ${ }^{£} p<0.05,{ }^{£ £} p<0.01,{ }^{£ £ f} p<0.001$ compared to baseline control group

effects of a 6-week exercise intervention in SD rats where animals were forced to swim for $1 \mathrm{~h} / \mathrm{d}$ on 5 days/week [2]. Animals that received a high-fat diet showed a decrease in TC and TG when compared to sedentary controls. In our study, the administration of a HFD increased TG, but not TC. Furthermore, exercise did not show a modulatory effect on TG, TC, or non-HDL-C. When compared to the present results, the lipid concentrations reported by Elmas et al. are quite different. These contrasting results may be explained the use of male animals that were considerably younger at the time of sacrification. Furthermore, the present study used a HFD with a different lipid composition and a less vigorous exercise intervention. Analytical differences may also have contributed to the different results. In our laboratory, all methods are strictly controlled by internal and external quality controls. Furthermore, the lipid concentrations that 
a

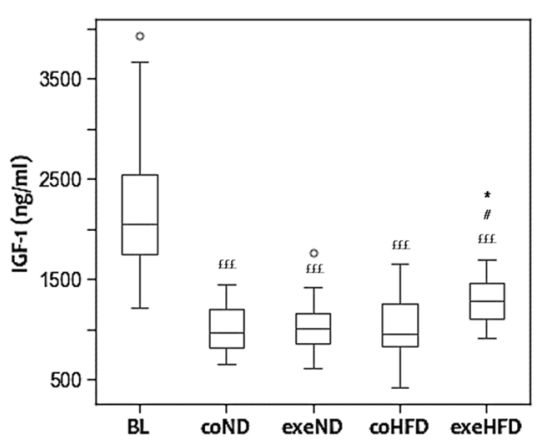

b

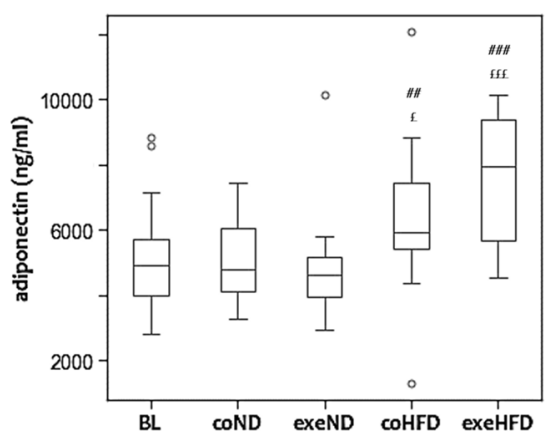

C

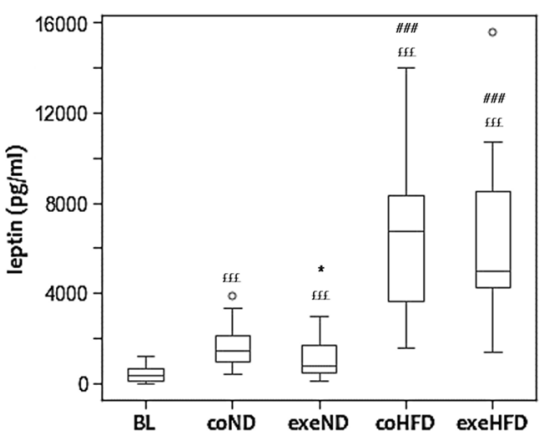

Fig. 6 Box and Whisker Blot of IGF-1 (a), adiponectin (b) and leptin $(\mathbf{c}) .{ }^{*} p<0.05$ compared to appropriate sedentary control group; ${ }^{*} p<0.05$, ${ }^{\# \#} p<0.01,{ }^{\# \# \#} p<0.001$ compared to appropriate normal diet control group. ${ }^{£} p<0.05,{ }^{£ £ f} p<0.001$ compared to baseline control group

we obtained in young and old control animals are in line with a previous study in SD rats [11].

The HFD used in this study is particularly rich in SFA and MUFA and thus induces an imbalance of lipoprotein metabolism with consequent alterations of plasma lipoproteins. According to the manufacturer, this diet aims to mimic the situation in humans who follow a typical Western-type dietary regimen and live in an obesogenic environment. Furthermore, it reliably induces obesity and metabolic syndrome in mice and rats. Differences in the dietary lipid composition may explain differences in plasma lipoproteins and oxidative-nitrosative stress markers observed in other HFD intervention studies in rodents [2, 23, 41, 42]. The current National Cholesterol Education Program (NCEP) and American Heart Association (AHA) dietary guidelines recommend limiting fat intake to $30-40 \%$ of the total dietary calories [43]. However, increasing fat intake inside the recommended range may already have adverse effects on the lipid profile with increasing TC and LDL-C concentrations [43]. In contrast, reducing fat intake to $20 \%$ or less can also be troublesome due to a reduction of LDL-C and HDL-C and a contemporary rise in TG. This combination is typically associated with the formation of small and dense LDL particles with a high atherogenic potential [43]. With the aim to promote a healthier LDL/HDL ratio, the original AHA Step I fat recommendation advices for a 1:1:1 proportion of SFA: MUFA: PUFA in the diet.

In old animals the lipid profile was substantially different from that of young animals with markedly higher TC and TG concentrations. Moreover, HDL-C, non-HDL-C and NEFA were higher in old than in young animals. Such agerelated changes of the lipid profile are expected and have been described by others before [44]. With the HFD used in this study, the concentrations of TG and NEFA increased, whereas all other parameters of the lipid profile remained unchanged. Previous studies that treated rodents with HFD reported mixed results. While some studies found increasing concentrations of TC, TG and LDL-C [2, 25, 41, 44] others did not [11]. However, a direct comparison of these studies is limited due to differences in study design and composition of the diets. For example, in 4-8-week-old Wistar rats the administration of HFD for 4-8 weeks resulted in increased body weight and adipose tissue weight, TC, TG, LDL-C concentrations [23, 42]. However, both studies did not include baseline measurements, which impedes a longitudinal evaluation of age-related effects. Zelzer et al. treated adult female SD rats for 12 weeks with a HFD comparable to the one used in the present study [11]. This intervention did not result in different TC or TG concentrations. Also, HDL-C and non-HDL-C were comparable between controls and HFD-treated animals. The limited comparability of different animal models is not surprising and has already been shown before [44]. Similar to animal models, also human studies that compared the lipid profile of obese and nonobese individuals yielded heterogeneous results [20, 21, 45]. Most existing studies showed higher TC, TG, LDL-C, and small dense LDL-C (sdLDL-C) concentrations in obese individuals when compared to normal weight controls. However, for HDL-C, inconsistent results have been reported [21, 45]. A controlled dietary intervention study by Egert et al. demonstrated that the substitution of a high-fat diet rich in saturated fatty acids with either a high-fat or a low-fat diet rich in mono-unsaturated fatty acids ameliorated the lipid profile, reducing TC, LDL-C/HDL-C ratio, LDL-C size and its susceptibility to oxidation [46].

A main finding of our study is the exercise-induced increase in oxLDL that is accompanied by a reduction of NO. Elevated oxidative stress is a common condition in sedentary and obese individuals that increases the generation of ROS and leads to the modification of many biochemical targets [8-10] including LDL-C. OxLDL is supposed to be more aggressive than non-oxidized LDL in driving inflammation, atherogenesis, and ultimately the risk of CVD events [5-7]. Nevertheless, exercise-induced ROS production 
seems to protect cells against oxidation by maintaining the cellular oxidant-antioxidant homeostasis [47, 48]. Furthermore, regular physical activity improves blood pressure control through an increased production of NO and other vasoactive substances [10]. In the present study, however, long-term moderate running exercise was associated with an increase in oxLDL and a reduction in NOx. While the increase in oxLDL was comparable in both dietary groups, the reduction in NOx was more pronounced in HFD animals. These results are in agreement with previous studies demonstrating an increased susceptibility of LDL-C and other lipoproteins to oxidation after a single intensive exercise session [3, 4]. Furthermore, in another study by Zelzer et al., the administration of a similar HFD to rats increased several markers of oxidative stress, such as malondialdehyde, but not oxLDL [11]. While Zelzer et al. measured oxLDL by ELISA, the other studies analysed lipoprotein oxidation indirectly [3, 4], which limits the comparability of results. When interpreting the modification of oxidative stress biomarkers by physical activity, it should be considered that chronic exercise as well as high-intensity training can increase oxidative stress through several mechanisms including increased mitochondrial oxygen consumption and activation of oxidase enzymes such as nicotinamide adenine dinucleotide phosphate (NADPH) oxidase, a major source of ROS [9]. This might at least partially explain the exerciseinduced increase in oxLDL that we observed in the present study. Additional support for this hypothesis comes from the reduction in NOx by regular exercise. Under normal circumstances, the potent vasodilator $\mathrm{NO}$ is released during the conversion of $\mathrm{L}$-arginine to L-citrulline. This reaction is catalysed by NOS. However, under certain circumstances, NOS can also produce superoxide $\left(\mathrm{O} 2^{*-}\right)$, which reacts avidly with vascular $\mathrm{NO}^{-}$to form peroxynitrite $\left(\mathrm{ONOO}^{-}\right)$. This metabolite is capable of impairing NOS dimerization and function [8, 49], which is called NOS-uncoupling. Such an uncoupling of NOS can occur in the absence of either $\mathrm{L}-\mathrm{arg}$ or $\mathrm{BH} 4$, and increased concentrations of ADMA, a competitive inhibitor of NOS. In the present study, HFD and regular exercise increased $\mathrm{h}$-arg, another substrate of NOS for the production of NO. Although h-arg competes with L-arg for NOS-binding sites, it seems to be a less efficient substrate for NO synthesis. According to März et al., the role of h-arg in NO metabolism is still insufficiently understood [50]. Some studies support the hypothesis that $\mathrm{h}$-arg might increase arginine bioavailability by inhibition of the enzyme arginase, which competes with NOS for the utilization of the key substrate $\mathrm{L}-\arg [50,51]$. If this is correct, the substantial increase in h-arg is likely to exert a protective effect under HFD. This concept is supported by a previous study showing that $\mathrm{h}$-arg supplementation ameliorates blood glucose in mice on HFD [52]. The reduction of ADMA and SDMA observed in the present study further supports the beneficial effect of h-arg in HFD animals. However, h-arg competes with L-arg in more than one way. They both utilize the same transport system for cell entry, and high extracellular h-arg concentrations will result in reduced L-arg uptake [53]. This might at least partially explain the exercise-induced reduction of NOx. The inverse relationship between oxLDL and NOx strongly supports the concept of NOS uncoupling in exercising animals. Considering that NOx levels were lower in non-exercising HFD animals than in non-exercising ND animals, HFD consumption seems to have an independent NO-reducing effect, which is amplified by regular exercise. The very low NOx concentration in exercising HFD animals further supports the concept of an additive NO-reducing effect of HFD and exercise.

In this project, we also investigated the influence of regular exercise on the adipokine, cytokine and chemokine profile in both dietary groups. Obesity is typically associated with an increased secretion of adipokines and a mild tissue inflammation [36]. As expected, our HFD animals showed markedly higher leptin and adiponectin serum concentrations than ND animals regardless of exercise, whereas IGF-1 and resistin were comparable in both dietary groups. Insulin was not considered as blood was collected non-fasting. Exercise was effective in reducing leptin in ND, but not HFD, animals suggesting that the HFD overwhelmed the effect of exercise. The mild increase in serum adiponectin in exeHFD animals might simply reflect the weight loss in these animals. Interestingly, the HFD used in this study had only minor pro-inflammatory effects inducing increased serum concentrations only for MCP-1 and IL-5. Other proinflammatory cytokines, such as TNF- $\alpha$, IFN- $\gamma$ or IL- 6 were comparable between the two dietary groups.

Consistent with previous studies [26, 54], our exercise protocol significantly reduced the serum concentrations of TNF- $\alpha$, IL- $1 \beta$, IL-2, MCP-1, MCP-3 and RANTES in HFD animals. MCP-3 and RANTES were also decreased in the exeND group. Both chemokines regulate the migration and infiltration of monocytes and macrophage into solid tissues [33]. The present results are in line with recent findings from Rocha-Rodrigues et al. showing that regular physical activity reduces inflammation in response to HFD administration [26]. Borst et al. have shown that in the context of obesity, visceral fat derived resistin, TNF- $\alpha$ and several other interleukins contribute to insulin resistance [35], whereas weight loss or visceral fat removal decrease serum IL- 6 and increase the insulin sensitizing hormone adiponectin $[34,35]$. The exercise-induced increase of IP-10, IL-12, and MMP activity in ND animals might reflect a mild activation of cellular immunity and tissue remodelling in response to exercise, which is masked in the HFD animals.

The present study has several strengths and limitations that should be considered when interpreting the results. The rather long intervention period with sufficiently sized groups 
allows robust conclusions about the effects of the different diets and physical activity as important modifiable lifestyle factors that impact CVD risk. Furthermore, our exercise protocol was well controlled and imitated a realistic activity regimen that would normally be considered as healthy. Another strength of this study is the use of validated and strictly quality controlled methods for the measurement of serum lipids. The unlimited access of the animals to food allowed them to compensate the exercise-related increase in energy expenditure through higher food consumption. Due to the unlimited access to food, we cannot account for natural occurring differences in food intake. Furthermore, we lack metabolic studies and blood collections were performed in a non-fasting state. Although this may have an impact on the results of several metabolic biomarkers, we intentionally decided to perform non-fasting blood collections to avoid unwanted psychological stress in the animals. It should also be mentioned that our method for the measurement of TG does not distinguish between TG and free glycerol. However, the blood concentration of free glycerol is $<1 \mathrm{mg} / \mathrm{dL}$, which accounts for approximately $10 \mathrm{mg} / \mathrm{dl}$ of triglycerides [55]. Considering that in the SD rats used in this study TG concentrations ranged between 100 and $400 \mathrm{mg} / \mathrm{dl}$, the unintentional detection of free glycerol does not represent a relevant confounder of our results.

Another weakness of our study is the lack of mechanistic information on the effects of exercise on plasma lipids. Considering that body weight was strongly correlated with TG, it can be speculated that the higher fatty acid intake in HFD animals, was the main driver of differences in plasma TG. The HFD used in this study contains approximately $60 \%$ of SFA and MUFA, which are incorporated into TG. Exercise instead, induced only minor differences in body weight and plasma lipids. This is not surprising, as our exercise regimen was rather moderate. Previous studies have shown that exercise induces beneficial effects on plasma lipids and lipoprotein lipase activity only above a certain threshold of energy expenditure [56,57]. Another putative mediator of plasma lipids could be adiponectin, which is known to increase energy expenditure through fatty acid oxidation in target organs, such as liver and skeletal muscle [58]. This theory is supported by the inverse correlations of TC and HDL-C with adiponectin.

\section{Conclusion}

In summary, long-term moderate exercise may alter the delicate equilibrium between oxidative and anti-oxidative compounds leading to an uncoupling of NOS with higher oxLDL and lower NOx concentrations.

However, these metabolic effects do not necessarily compromise the beneficial reduction of pro-inflammatory cytokines, such as TNF- $\alpha$, IL- $1 \beta$, IL-2, MCP-1, MCP-3 and RANTES. This conundrum adds to the controversial role of oxLDL in pathologic developments like atherosclerosis and CVD and should trigger additional research that helps to understand lipoprotein oxidation and NO production in response to exercise and different dietary habits.

Acknowledgements The authors thank the Core Facility Experimental Biomodels, Division of Biomedical Research of the Medical University of Graz, $8036 \mathrm{Graz}$ (Austria), for housing our animal model and for all the support during the training period. The authors would like to also thank Stefano Luigi Cardia for his valuable help in organising and plotting the data.

Authors' contributions Conceived and designed the experiments: $\mathrm{MH}$, H-JG, GA; performed the experiments: MDS, H-JG, GA, SZ, AM, HS; data analysis and assessment: MDS, H-JG, GA; wrote the original draft of the paper: MDS; reviewed and edited the paper: $\mathrm{H}-\mathrm{JG}, \mathrm{MH}$; contribution to the critical appraisal of the paper: GA, MK, SZ, AM, HS, SS, H-JG, MH.

Funding Open access funding provided by Medical University of Graz.

Availability of data and materials All data and materials as well as software application or custom code support their published claims and comply with field standards.

Code availability Not applicable.

\section{Declarations}

Conflict of interest The authors declare that no conflict of interests influenced the work reported in this paper.

Ethics approval The study was approved by the responsible national ethics committee (GZ: 66.010/0070-V/3b/2018) and performed in accordance with the guidelines of the Animal Care and Use Committee of the Ministry of Science and Research, Vienna, Austria.

Open Access This article is licensed under a Creative Commons Attribution 4.0 International License, which permits use, sharing, adaptation, distribution and reproduction in any medium or format, as long as you give appropriate credit to the original author(s) and the source, provide a link to the Creative Commons licence, and indicate if changes were made. The images or other third party material in this article are included in the article's Creative Commons licence, unless indicated otherwise in a credit line to the material. If material is not included in the article's Creative Commons licence and your intended use is not permitted by statutory regulation or exceeds the permitted use, you will need to obtain permission directly from the copyright holder. To view a copy of this licence, visit http://creativecommons.org/licenses/by/4.0/.

\section{References}

1. Annex TWHR-S (2004) Deaths by cause, sex and mortality stratum in WHO regions, estimates for 2002, Annex Table 2. https:// www.who.int/whr/2004/annex/topic/en/annex_2_en.pdf?ua=1. Accessed 15 Jan 2020 
2. Acikel Elmas M, Cakıcı SE, Dur IR, Kozluca I, Arınc M, Binbuga B, Bingol Ozakpınar O, Kolgazi M, Sener G, Ercan F (2019) Protective effects of exercise on heart and aorta in high-fat dietinduced obese rats. Tissue Cell 57:57-65. https://doi.org/10. 1016/j.tice.2019.01.005

3. Kaikkonen J, Porkkala-Sarataho E, Tuomainen TP, Nyyssönen K, Kosonen L, Ristonmaa U, Lakka HM, Salonen R, Korpela H, Salonen JT (2002) Exhaustive exercise increases plasma/serum total oxidation resistance in moderately trained men and women, whereas their VLDL + LDL lipoprotein fraction is more susceptible to oxidation. Scand J Clin Lab Invest 62(8):599-607. https:// doi.org/10.1080/003655102764654330

4. Medlow P, McEneny J, Murphy M, Trinick T, Duly E, Davison $G$ (2015) Lipoprotein subfraction oxidation in acute exercise and aging. Free Radical Res 50:1-30. https://doi.org/10.3109/10715 762.2015.1109084

5. Trpkovic A, Resanovic I, Stanimirovic J, Radak D, Mousa SA, Cenic-Milosevic D, Jevremovic D, Isenovic ER (2015) Oxidized low-density lipoprotein as a biomarker of cardiovascular diseases. Crit Rev Clin Lab Sci 52(2):70-85. https://doi.org/10.3109/10408 363.2014.992063

6. Chis IC, Coseriu A, Simedrea R, Oros A, Nagy AL, Clichici S (2015) In vivo effects of quercetin in association with moderate exercise training in improving streptozotocin-induced aortic tissue injuries. Molecules 20(12):21770-21786. https://doi.org/10.3390/ molecules201219802

7. Verhoye E, Langlois MR (2009) Circulating oxidized low-density lipoprotein: a biomarker of atherosclerosis and cardiovascular risk? Clin Chem Lab Med 47(2):128-137. https://doi.org/10.1515/ cclm.2009.037

8. Förstermann U, Münzel T (2006) Endothelial nitric oxide synthase in vascular disease: from marvel to menace. Circulation 113(13):1708-1714. https://doi.org/10.1161/circulationaha.105. 602532

9. Powers SK, Radak Z, Ji LL (2016) Exercise-induced oxidative stress: past, present and future. J Physiol 594(18):5081-5092. https://doi.org/10.1113/jp270646

10. Fernandes T, Gomes-Gatto CV, Pereira NP, Alayafi YR, das Neves VJ, Oliveira EM (2017) NO signaling in the cardiovascular system and exercise. Adv Exp Med Biol 1000:211-245. https://doi.org/ 10.1007/978-981-10-4304-8_13

11. Zelzer S, Mangge H, Pailer S, Ainoedhofer H, Kieslinger P, Stojakovic T, Scharnagl H, Prüller F, Weghuber D, Datz C (2015) Oxidized LDL is strictly limited to hyperthyroidism irrespective of fat feeding in female Sprague Dawley rats. Int J Mol Sci 16(5):11689-11698

12. Maiorana A, O’Driscoll G, Taylor R, Green D (2003) Exercise and the nitric oxide vasodilator system. Sports Med 33(14):10131035. https://doi.org/10.2165/00007256-200333140-00001

13. Saraiva RM, Hare JM (2006) Nitric oxide signaling in the cardiovascular system: implications for heart failure. Curr Opin Cardiol 21(3):221-228. https://doi.org/10.1097/01.hco.0000221584. 56372.dc

14. Lundberg JO, Gladwin MT, Weitzberg E (2015) Strategies to increase nitric oxide signalling in cardiovascular disease. Nat Rev Drug Discov 14(9):623-641. https://doi.org/10.1038/nrd4623

15. Ghimire K, Altmann HM, Straub AC, Isenberg JS (2017) Nitric oxide: what's new to NO? Am J Physiol Cell Physiol 312(3):C254-c262. https://doi.org/10.1152/ajpcell.00315.2016

16. Fernandes T, Magalhães FC, Roque FR, Phillips MI, Oliveira EM (2012) Exercise training prevents the microvascular rarefaction in hypertension balancing angiogenic and apoptotic factors: role of microRNAs-16, -21, and -126. Hypertension 59(2):513-520. https://doi.org/10.1161/hypertensionaha.111.185801

17. Fernandes T, Nakamuta JS, Magalhães FC, Roque FR, LaviniRamos C, Schettert IT, Coelho V, Krieger JE, Oliveira EM (2012)
Exercise training restores the endothelial progenitor cells number and function in hypertension: implications for angiogenesis. $\mathbf{J}$ Hypertens 30(11):2133-2143. https://doi.org/10.1097/HJH.0b013 e3283588d46

18. Roque FR, Briones AM, García-Redondo AB, Galán M, Martínez-Revelles S, Avendaño MS, Cachofeiro V, Fernandes T, Vassallo DV, Oliveira EM, Salaices M (2013) Aerobic exercise reduces oxidative stress and improves vascular changes of small mesenteric and coronary arteries in hypertension. Br J Pharmacol 168(3):686-703. https://doi.org/10.1111/j.1476-5381.2012. 02224.x

19. Ren J, Yang L, Tian W, Zhu M, Liu J, Lu P, Li J, Yang L, Qi Z (2015) Nitric oxide synthase inhibition abolishes exercise-mediated protection against isoproterenol-induced cardiac hypertrophy in female mice. Cardiology 130(3):175-184. https://doi.org/10. $1159 / 000370025$

20. Suzuki K, Ito Y, Ochiai J, Kusuhara Y, Hashimoto S, Tokudome S, Kojima M, Wakai K, Toyoshima H, Tamakoshi K, Watanabe Y, Hayakawa N, Maruta M, Watanabe M, Kato K, Ohta Y, Tamakoshi A (2003) Relationship between obesity and serum markers of oxidative stress and inflammation in Japanese. Asian Pac J Cancer Prev 4(3):259-266

21. Gómez-Martin JM, Balsa JA, Aracil E, Cuadrado-Ayuso M, Rosillo M, De la Peña G, Lasunción MA, Escobar-Morreale HF, Botella-Carretero JI (2018) Beneficial changes on plasma apolipoproteins A and B, high density lipoproteins and oxidized low density lipoproteins in obese women after bariatric surgery: comparison between gastric bypass and sleeve gastrectomy. Lipids Health Dis 17(1):145. https://doi.org/10.1186/s12944-018-0794-5

22. Koh Y, Park J, Carter R (2018) Oxidized low-density lipoprotein and cell adhesion molecules following exercise training. Int $\mathbf{J}$ Sports Med 39(2):83-88. https://doi.org/10.1055/s-0043-118848

23. Matsuo T, Takeuchi H, Suzuki H, Suzuki M (2002) Body fat accumulation is greater in rats fed a beef tallow diet than in rats fed a safflower or soybean oil diet. Asia Pac J Clin Nutr 11(4):302-308. https://doi.org/10.1046/j.1440-6047.2002.00299.x

24. Li W, Wang D, Song G, Zuo C, Qiao X, Qin S (2010) The effect of combination therapy of allicin and fenofibrate on high fat diet-induced vascular endothelium dysfunction and liver damage in rats. Lipids Health Dis 9:131. https://doi.org/10.1186/ 1476-511x-9-131

25. Bhandari U, Kumar V, Khanna N, Panda BP (2011) The effect of high-fat diet-induced obesity on cardiovascular toxicity in Wistar albino rats. Hum Exp Toxicol 30(9):1313-1321. https://doi.org/ 10.1177/0960327110389499

26. Rocha-Rodrigues S, Rodríguez A, Gonçalves IO, Moreira A, Maciel E, Santos S, Domingues MR, Frühbeck G, Ascensão A, Magalhães J (2017) Impact of physical exercise on visceral adipose tissue fatty acid profile and inflammation in response to a high-fat diet regimen. Int J Biochem Cell Biol 87:114-124. https:// doi.org/10.1016/j.biocel.2017.04.008

27. Li FH, Sun L, Zhu M, Li T, Gao HE, Wu DS, Zhu L, Duan R, Liu TC (2018) Beneficial alterations in body composition, physical performance, oxidative stress, inflammatory markers, and adipocytokines induced by long-term high-intensity interval training in an aged rat model. Exp Gerontol 113:150-162. https://doi.org/10. 1016/j.exger.2018.10.006

28. Rao Z, Wang S, Bunner WP, Chang Y, Shi R (2018) Exercise induced right ventricular fibrosis is associated with myocardial damage and inflammation. Korean Circ J 48(11):1014-1024. https://doi.org/10.4070/kcj.2018.0084

29. Ji N, Luan J, Hu F, Zhao Y, Lv B, Wang W, Xia M, Zhao X, Lao K (2018) Aerobic exercise-stimulated Klotho upregulation extends life span by attenuating the excess production of reactive oxygen species in the brain and kidney. Exp Ther Med 16(4):3511-3517. https://doi.org/10.3892/etm.2018.6597 
30. Teerlink T, Nijveldt RJ, de Jong S, van Leeuwen PAM (2002) Determination of arginine, asymmetric dimethylarginine, and symmetric dimethylarginine in human plasma and other biological samples by high-performance liquid chromatography. Anal Biochem 303(2):131-137. https://doi.org/10.1006/abio.2001.5575

31. Meinitzer A, Puchinger M, Winklhofer-Roob BM, Rock E, Ribalta J, Roob JM, Sundl I, Halwachs-Baumann G, März W (2007) Reference values for plasma concentrations of asymmetrical dimethylarginine (ADMA) and other arginine metabolites in men after validation of a chromatographic method. Clin Chim Acta 384(1):141-148. https://doi.org/10.1016/j.cca.2007.07.006

32. Ohta R, Kumagai F, Marumo H, Usumi K, Saito Y, Kuwagata M (2016) Stress-reactive rats (high-avoidance female rats) have a shorter lifespan than stress-nonreactive rats (low-avoidance female rats). J Toxicol Pathol 29(2):77-84. https://doi.org/10.1293/tox. 2015-0045

33. Gong J-H, Uguccioni M, Dewald B, Baggiolini M, Clark-Lewis I (1996) RANTES and MCP-3 antagonists bind multiple chemokine receptors (*). J Biol Chem 271(18):10521-10527. https://doi.org/ 10.1074/jbc.271.18.10521

34. Yang WS, Lee WJ, Funahashi T, Tanaka S, Matsuzawa Y, Chao CL, Chen CL, Tai TY, Chuang LM (2001) Weight reduction increases plasma levels of an adipose-derived anti-inflammatory protein, adiponectin. J Clin Endocrinol Metab 86(8):3815-3819. https://doi.org/10.1210/jcem.86.8.7741

35. Borst SE, Conover CF, Bagby GJ (2005) Association of resistin with visceral fat and muscle insulin resistance. Cytokine 32(1):39-44. https://doi.org/10.1016/j.cyto.2005.07.008

36. Fuster JJ, Ouchi N, Gokce N, Walsh K (2016) Obesity-induced changes in adipose tissue microenvironment and their impact on cardiovascular disease. Circ Res 118(11):1786-1807. https://doi. org/10.1161/CIRCRESAHA.115.306885

37. Holme I, Høstmark AT, Anderssen SA (2007) ApoB but not LDLcholesterol is reduced by exercise training in overweight healthy men. Results from the 1 year randomized Oslo diet and exercise study. J Intern Med 262(2):235-243. https://doi.org/10.1111/j. 1365-2796.2007.01806.x

38. Wang Y, Xu D (2017) Effects of aerobic exercise on lipids and lipoproteins. Lipids Health Dis 16(1):132. https://doi.org/10.1186/ s12944-017-0515-5

39. Muscella A, Stefàno E, Marsigliante S (2020) The effects of exercise training on lipid metabolism and coronary heart disease. Am J Physiol Heart Circ Physiol 319(1):H76-h88. https://doi.org/10. 1152/ajpheart.00708.2019

40. Leon AS, Rice T, Mandel S, Després JP, Bergeron J, Gagnon J, Rao DC, Skinner JS, Wilmore JH, Bouchard C (2000) Blood lipid response to 20 weeks of supervised exercise in a large biracial population: the HERITAGE family study. Metabolism 49(4):513520. https://doi.org/10.1016/s0026-0495(00)80018-9

41. Ko K, Woo J, Bae JY, Roh HT, Lee YH, Shin KO (2018) Exercise training improves intramuscular triglyceride lipolysis sensitivity in high-fat diet induced obese mice. Lipids Health Dis 17(1):81. https://doi.org/10.1186/s12944-018-0730-8

42. Shatoor AS, Al Humayed S, Alkhateeb MA, Shatoor KA, Aldera H, Alassiri M, Shati AA (2019) Crataegus Aronia protects and reverses vascular inflammation in a high fat diet rat model by an antioxidant mechanism and modulating serum levels of oxidized low-density lipoprotein. Pharm Biol 57(1):38-48. https://doi.org/ 10.1080/13880209.2018.1564930

43. Hayes K (2002) Dietary fat and heart health: in search of the ideal fat. Asia Pac J Clin Nutr 11(Suppl 7):S394-400. https://doi.org/ 10.1046/j.1440-6047.11.s.7.13.x

44. Udomkasemsab A, Prangthip P (2019) High fat diet for induced dyslipidemia and cardiac pathological alterations in Wistar rats compared to Sprague Dawley rats. Clin Investig Arterioscler 31(2):56-62. https://doi.org/10.1016/j.arteri.2018.09.004

45. Mutlu-Türkoğlu U, Oztezcan S, Telci A, Orhan Y, Aykaç-Toker G, Sivas A, Uysal M (2003) An increase in lipoprotein oxidation and endogenous lipid peroxides in serum of obese women. Clin Exp Med 2(4):171-174. https://doi.org/10.1007/s102380300002

46. Egert S, Kratz M, Kannenberg F, Fobker M, Wahrburg U (2011) Effects of high-fat and low-fat diets rich in monounsaturated fatty acids on serum lipids, LDL size and indices of lipid peroxidation in healthy non-obese men and women when consumed under controlled conditions. Eur J Nutr 50(1):71-79. https://doi.org/10. 1007/s00394-010-0116-9

47. Silveira LR, Pilegaard H, Kusuhara K, Curi R, Hellsten Y (2006) The contraction induced increase in gene expression of peroxisome proliferator-activated receptor (PPAR) $-\gamma$ coactivator $1 \alpha(\mathrm{PGC}-1 \alpha)$, mitochondrial uncoupling protein 3 (UCP3) and hexokinase II (HKII) in primary rat skeletal muscle cells is dependent on reactive oxygen species. Biochim Biophys Acta (BBA)-Mol Cell Res 1763(9):969-976

48. Ji LL, Gomez-Cabrera MC, Vina J (2006) Exercise and hormesis: activation of cellular antioxidant signaling pathway. Ann NY Acad Sci 1067(1):425-435

49. Förstermann U, Sessa WC (2012) Nitric oxide synthases: regulation and function. Eur Heart J 33(7):829-837

50. März W, Meinitzer A, Drechsler C, Pilz S, Krane V, Kleber ME, Fischer J, Winkelmann BR, Böhm BO, Ritz E, Wanner C (2010) Homoarginine, cardiovascular risk, and mortality. Circulation 122(10):967-975. https://doi.org/10.1161/CIRCULATIONAHA. 109.908988

51. Hrabak A, Bajor T, Temesi A (1994) Comparison of substrate and inhibitor specificity of arginase and nitricm oxide (NO) synthase for arginine analogs and related compounds in murine and rat macrophages. Biochem Biophys Res Commun 198(1):206-212. https://doi.org/10.1006/bbrc.1994.1029

52. Stockebrand M, Hornig S, Neu A, Atzler D, Cordts K, Böger R, Isbrandt D, Schwedhelm E, Choe C-U (2015) Homoarginine supplementation improves blood glucose in diet-induced obese mice. Amino Acids. https://doi.org/10.1007/s00726-015-2022-1

53. van der Zwan LP, Davids M, Scheffer PG, Dekker JM, Stehouwer CDA, Teerlink T (2013) L-Homoarginine and L-arginine are antagonistically related to blood pressure in an elderly population: the Hoorn study. J Hypertens 31(6):1114-1123. https://doi.org/10. 1097/HJH.0b013e32836037fb

54. Oliveira AG, Araujo TG, Carvalho BM, Guadagnini D, Rocha GZ, Bagarolli RA, Carvalheira JBC, Saad MJ (2013) Acute exercise induces a phenotypic switch in adipose tissue macrophage polarization in diet-induced obese rats. Obesity 21(12):2545-2556

55. Speeckaert MM, Segers H, Van Biesen W, Verstraete A, Langlois MR, Delanghe JR (2010) An unusual case of (pseudo)hypertriglyceridaemia. NDT Plus 3(6):570-572. https://doi.org/10.1093/ ndtplus/sfq148

56. Ferguson MA, Alderson NL, Trost SG, Essig DA, Burke JR, Durstine JL (1998) Effects of four different single exercise sessions on lipids, lipoproteins, and lipoprotein lipase. J Appl Physiol (1985) 85(3):1169-1174. https://doi.org/10.1152/jappl.1998.85.3. 1169

57. Mann S, Beedie C, Jimenez A (2014) Differential effects of aerobic exercise, resistance training and combined exercise modalities on cholesterol and the lipid profile: review, synthesis and recommendations. Sports Med 44(2):211-221. https://doi.org/10.1007/ s40279-013-0110-5

58. Achari AE, Jain SK (2017) Adiponectin, a therapeutic target for obesity, diabetes, and endothelial dysfunction. Int J Mol Sci 18(6):1321. https://doi.org/10.3390/ijms18061321 